\title{
Pioneering Al, Data Science and Multimedia Techniques and Findings for COVID-19
}

Published online: 6 January 2022

(c) Springer Science+Business Media, LLC, part of Springer Nature 2021

Multimedia Tools and Applications gratefully acknowledges the editorial work of the scholars listed below on the special issue entitled "Pioneering AI, Data Science and Multimedia Techniques and Findings for COVID-19”' (SI 1192).

Of 31 papers submitted, 2 were accepted for this issue after a stringent peer review process.

\section{Corresponding Guest Editor}

Victor Chang

Teesside University, UK

Email: V.Chang@tees.ac.uk

Guest Editors

Muthu Ramachandran

Leeds Beckett University, UK

Email: M.Ramachandran@ leedsbeckett.ac.uk

Víctor Méndez Muñoz

Universitat Oberta de Catalunya, Barcelona, Spain

Email: vmendezmu@uoc.edu

Publisher's note Springer Nature remains neutral with regard to jurisdictional claims in published maps and institutional affiliations. 